\section{Géneros}

Multidisciplinary Journal of Gender: Studies

\section{Hipatia Press}

www.hipatiapress.com

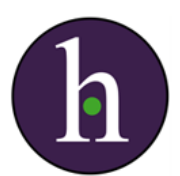

Instructions for authors, subscriptions and further details:

http://generos.hipatiapress.com

\title{
Género desde una perspectiva global
}

Daniel Leal González ${ }^{1}$

1) Universidad de las Islas Baleares. Spain

Date of publication: February $25^{\text {th }}, 2019$

Edition period: February-June 2019

To cite this article: Leal González, D. (2019). Género desde una perspectiva global. Multidisciplinary Journal of Gender Studies, 8(1), 106107. doi: 10.17583/generos.2019.3905

To link this article: $\underline{\text { http://dx.doi.org/10.17583/generos.2019.3905 }}$

\section{PLEASE SCROLL DOWN FOR ARTICLE}

The terms and conditions of use are related to the Open Journal System and to Creative Commons Attribution License (CC-BY). 
February 2019 pp. 106-107

\section{Review}

Connell, R. \& Pearse, R. (2018). Género desde una perspectiva global. Valencia: Universitat de València. Traducción de Arantxa Grau i Muñoz y Almudena A. Navas Saurin. ISBN: 978-84-9134-273-1.

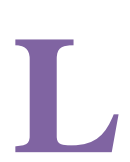

a edición al castellano de esta obra de las doctoras Raewyn Connell y Rebecca Pearse es una gran noticia en el ámbito de los estudios feministas y de género. Este texto nos sumerge en las implicaciones teóricas y epistemológicas de los órdenes de género históricamente construidos y cómo condicionan nuestras formas de pensarnos, relacionarnos y hacer en nuestras vidas cotidianas. Todo ello en el marco de una cuidada edición y una esmerada traducción que hace que la lectura de las casi trescientas páginas de la obra sea una experiencia fluida, rica, y por momentos apasionante.

Raewyn Connell es socióloga, catedrática jubilada de la Universidad de Sidney y una referencia internacional en los estudios de género y masculinidades. La doctora Rebecca Pearse es profesora en el Departamento de Economía Política de la misma universidad. El libro está estructurado en ocho capítulos con prefacio y coda, y cuenta con un prólogo de las traductoras de la obra, en el que se esboza la propuesta teórica del modelo de Connell y la aplicación práctica del mismo en la colonización de la denominada Nueva España.

Género desde una perspectiva global nos presenta ocho capítulos de enjundia que avanzan en la consideración del género como una categoría históricamente construida, sujeta en su desarrollo a la agencia de estructuras de poder económico, institucionales y sociales. El primero de los capítulos enmarca y documenta las desigualdades sexistas desde una perspectiva global. El segundo muestra cinco investigaciones de distinto alcance realizadas con diferentes metodologías en cinco continentes. El tercero de los capítulos está dedicado a la diferencia sexual, abordando los conflictos

2019 Hipatia Press

ISSN: 2014-3613

doi: 10.17583/generos.2019.3905 
entre diferencia y similitud sexual y el desarrollo del concepto de arena reproductiva. El cuarto de los capítulos se dedica a la teoría y teóricas del género desarrollando ideas sobre la construcción de los órdenes del género en diferentes etapas históricas desde el colonialismo hasta la actualidad.

El núcleo fundamental de la propuesta teórica del libro se halla en el quinto capítulo en el que se describe un modelo multidimensional e interseccional de análisis de las estructuras de género, divididos en cuatro arenas: Poder, producción, catexis y simbolismo. Estas dimensiones pueden cambiar a través de la agencia de movimientos sociales como fundamentalmente el feminista. El sexto capítulo se dedica a la transcendencia de la categoría género en la vida personal y aborda la transición, lo transgénero y lo transexual. Para concluir con los capítulos séptimo y octavo que abordan tanto el género en relación con el desarrollo medioambiental, como a los estados, corporaciones empresariales internacionales y la economía global en perspectiva de género.

Género desde una perspectiva global es una obra ambiciosa, comprometida y muy poderosa que aspira a ser una referencia en su ámbito de estudio. Para ello, aborda de forma precisa la realidad presente en materia de igualdad entre mujeres y hombres y ofrece un modelo de análisis multidimensional para el estudio de las estructuras patriarcales como escenario de luchas políticas y sociales, y cómo condicionan la vida cotidiana de mujeres y hombres de todo el planeta. Nos encontramos pues, ante una obra de obligada revisión y lectura.

Daniel Antonio Leal González, Universidad de las Islas Baleares daniel.lealgonzalez@yahoo.es 